\title{
An experimental and numerical analysis of the influence of the inlet temperature, equivalence ratio and compression ratio on the HCCI auto- ignition process of Primary Reference Fuels in an engine
}

\author{
Hatim Machrafi*, Simeon Cavadias \\ UPMC Université Paris 06, LGPPTS, Ecole Nationale Supérieure de Chimie de Paris, 11, rue de Pierre et Marie \\ Curie, 75005 Paris, France \\ Tel.: +331442767 18; Fax: +33143265813
}

\begin{abstract}
In order to understand better the auto-ignition process in an HCCI engine, the influence of some important parameters on the auto-ignition is investigated. The inlet temperature, the equivalence ratio and the compression ratio were varied and their influence on the pressure, the heat release and the ignition delays were measured. The inlet temperature was changed from 25 to $70{ }^{\circ} \mathrm{C}$ and the equivalence ratio from 0.18 to 0.41 , while the compression ratio varied from 6 to 13.5. The fuels that were investigated were PRF40 and n-heptane. These three parameters appeared to decrease the ignition delays, with the inlet temperature having the least influence and the compression ratio the most. A previously experimentally validated reduced surrogate mechanism, for mixtures of n-heptane, iso-octane and toluene, has been used to explain observations of the auto-ignition process. The same kinetic mechanism is used to better understand the underlying chemical and physical phenomena that make the influence of a certain parameter change according to the operating conditions. This can be useful for the control of the auto-ignition process in an HCCI engine.
\end{abstract}

Key words: auto-ignition, HCCI engine, inlet temperature, equivalence ratio, compression ratio, PRF, kinetic mechanism

*Corresponding author.

E-mail address: hatim-machrafi@enscp.fr 


\section{Introduction}

Nowadays combustion engines are used enormously for all sorts of means. In the automobile industry, engines are mostly 4-stroke engines (intake stroke, compression stroke, combustion stroke and exhaust stroke) and generally there are two kinds of automobile engines: the Otto engine (Spark Ignition, SI) and the Diesel engine (Compression Ignition, CI). It seems reasonable to expect that the number of vehicles (with a combustion engine) will rise in the future, especially given factors such as the rapid economic development in densely populated areas. This will increase fuel consumption. Furthermore legislation restricts the amount of emissions emitted by the engines. To reduce the fuel consumption and the amount of emissions, an alternative is proposed, which seems to be very promising: the Homogeneous Charge Compression Ignition (HCCI). Diesel engines operate at higher compression ratios (12-24) than SI engines. In this type of engines, varying the amount of Diesel fuel injected into the cylinder controls the load. In a Diesel engine the air and the fuel are separately introduced into the engine. Instead of ignition by a spark plug, the air-fuel mixture autoignites due to compression. The alternative HCCI is a sort of hybrid of these two types of conventional engines and can be defined as a premixed, lean burn combustion process, preceded by a homogeneous air/fuel port-injection. The HCCI engine generally runs on a lean, diluted mixture of fuel, air and combustion products, which is not ignited by a spark but spontaneously (due to compression) instead. When implying HCCI combustion, the major problem that appears, is the control of the ignition delay. The idea is to investigate the impact of different parameters on the auto-ignition process in order to gain a better understanding of how the auto-ignition could be controlled. Several physical parameters affect the quality of the HCCI combustion and the ignition delay: mixture homogeneity, inlet temperature of air and fuel, fuel composition, equivalence ratio and kinetics of the fuel oxidation at lower temperatures [1-9]. The study of Maigaard et al. [10] reveals that the ignition delay is a 
function of turbulent mixing of the hot bulk and the colder boundary layer. A better understanding of the influence of these parameters on the ignition delay and the HCCI combustion is required, to have a more thorough knowledge of the HCCI combustion process and consequently of the application on an engine. Obviously, when one mentions an autoignition process study, one could think at a study of the auto-ignition delays. However, the auto-ignition delay is a result of various complex chemical, physical and energetic processes that take place during the auto-ignition process. For this purpose also the effect of the different parameters on the pressures and the heat releases should be investigated. These factors should represent the auto-ignition process as a whole. The ignition delays represent the chemistry; the pressure and the heat release represent the power, work, energy and heat involved. The main parameters, studied the most in the literature, are the inlet temperature, the equivalence ratio, the fuel structure and composition, the compression ratio, EGR and additives, observing generally either a one-stage combustion or a two-stage combustion, depending on the fuel $[\mathbf{1 , 2 , 4 , 6 - 1 4 ]}$. For the Primary Reference Fuels (PRF's), generally a twostage combustion is observed at low inlet temperatures.

The purpose of this paper has two parts that are treated in a parallel way. The first is to investigate experimentally the influence of the inlet temperature, the equivalence ratio and the compression ratio on the pressure, heat release and the ignition delays at HCCI engine operating mode. The second part, more importantly, is interested in the use of a kinetic mechanism for a deeper analysis. This mechanism should be used for HCCI engine operating conditions. For instance, the energetic content of the fuel, heat capacity changes and the influence of the residual gas on the kinetics, are other phenomena that can influence strongly the kinetics of the combustion. These phenomena can not be explained fully by analysing the trends found by the experiments. A kinetic mechanism should give a deeper insight in the aforementioned phenomena. Furthermore, a mechanism that shows the same trend as the 
experiments can be used for extrapolation or interpolation purposes, which reduce experimental costs. In previous work [15], a reduced kinetic mechanism for mixtures of nheptane, iso-octane and toluene has been validated experimentally. The advantage of such a mechanism is that the complex effects of each parameter can be treated separately. For instance, several aspects of the influence of the equivalence ratio can be analysed one by one by choosing the initial conditions such that only one effect is calculated. This is illustrated in the results and discussion section. This mechanism is used in this paper to back up the observations and to explain the findings. The investigation range of the parameters is an inlet temperature between 25 and $70{ }^{\circ} \mathrm{C}$, an equivalence ratio between 0.18 and 0.41 and a compression ratio between 6 and 14. The fuels that are used for this study are n-heptane and PRF40.

\section{Experimental}

The experimental set-up has already been discussed in previous work [15]. Some essential configurations, assumptions, error estimations and calculations will be recalled in this section. Table 1 shows the engine characteristics. The experimental set-up comprises a CFR engine, equipped with an air inlet system and a fuel nozzle injection system, being assisted by pressurized air. A mixture tank serves to mix the fuel as homogeneously as possible, measuring the air flow, the fuel flow, the inlet pressure and the inlet temperature (confidence interval $+/-1^{\circ} \mathrm{C}$ ). This allows calculating the equivalence ratio, with a confidence interval of +/- 0.005. The CFR engine has a variable compression ratio (confidence interval $+/-0.5$ ), being defined as the volumetrical ratio of the total volume (dead volume and displacement volume) and the dead volume. The fuel is composed by measuring the volumetric quantity (confidence interval $+/-1 \mathrm{vol} \%$ ) of each constituent of the fuel and mixing these together. For the post treatment of the experiments, the cylinder pressure is measured by a pressure sensor, 
exhibiting a standard deviation of the maximum pressure of around $0.12 \%$ for a motored pressure, but this can go up to about $1.5 \%$ at combustion and $3 \%$ for unstable combustion. This pressure allows investigating the behaviour of the auto-ignition process as a function of the aforementioned parameters. Another tool for this analysis is the ignition delay. As said before for PRF's, two-stage ignitions are observed, translated into a heat release with two maxima, the latter being higher than the former. The ignition delays are defined identically, the cool flame delay being the number of Crank Angle Degrees (CAD) from Bottom Dead Center (BDC) until the first heat release maximum and the final ignition delay being the number of $\mathrm{CAD}$ from $\mathrm{BDC}$ until the second heat release maximum. The heat release shows a confidence interval of $10 \%$ for the maximum and the ignition delays show a confidence interval of $+/-0.5 \mathrm{CAD}$. These ignition delays are calculated, by using a $0 \mathrm{D}$ engine model, calculating the heat release. The heat release, $d Q_{\text {release }} / \mathrm{d} \theta$ is calculated, using the following equation:

$$
\frac{d Q_{\text {release }}}{d \theta}=\frac{d Q_{\text {wall }}}{d \theta}+\frac{\gamma}{\gamma-1} P \frac{d V}{d \theta}+\frac{1}{\gamma-1} V \frac{d P}{d \theta}
$$

Here $\theta$ is the crank angle degree, while $d Q_{\text {wall }} / d \theta$ is the heat loss to the wall. The volume, $V$, is determined from the engine geometry and $\gamma$ is the isentropic constant $\left(\mathrm{C}_{\mathrm{p}} / \mathrm{C}_{\mathrm{v}}\right)$. The heat loss is calculated at each point in time according to:

$$
Q_{\text {wall }}=h A\left(T-T_{\text {wall }}\right)
$$

where the temperature $\mathrm{T}$ is estimated by using the gas temperature, calculated from the ideal gas law. $A$ is the surface of the cylinder. The wall temperature $T_{\text {wall, }}$, is estimated by measuring the heat loss to the cooling water and using the standard heat convection and conduction correlations. A heat transfer correlation that is adjusted for HCCI application [12] has been used in order to estimate the overall heat transfer correlation to the wall. Furthermore, for the use of the reduced kinetic model as explanation of the experimental 
findings, an estimation of the residual gas fraction and temperature has been performed in order to estimate more reallistically the temperature at inlet valve closing. More detail about the heat transfer, the estimation of the wall temperature and the estimation of the residual gas fraction and temperature, according to the experimental configuration of this paper, can be found in previous work [15].

\section{Results and discussion}

The chemistry of the auto-ignition of PRF's is well known. Since, the most important reactions play an important role in the understanding of the experimental findings, a global reminder of the chemical pathway of the auto-ignition is given first. The first reaction is the initiation reaction, in which n-heptane reacts with oxygen. After the H-abstraction step, the heptyl radical can subsequently react with molecular oxygen to form an alkylperoxy radical. This isomerizes (hydroperoxide) and another addition to oxygen takes place forming peroxy hydroperoxides. At increasing temperatures, this decomposes into hydroxyl radicals and ketohydroperoxides. When the temperature is high enough, the ketohydroperoxides decompose primarily into hydroxyl radicals, $\mathrm{CO}$, olefins, and aldehydes. These reactions and especially the consumption of the fuel by the hydroxyl radicals increase the system's pressure and temperature. This is called the cool flame. At this temperature zone, the hydroperoxides rather decompose into olefins, $\beta$-scission products and aldehydes. Also $\mathrm{H}_{2} \mathrm{O}_{2}$ is formed and is built up. These are relatively stable species that decrease the overall reactivity of the system at increasing temperature and delay the final ignition. This is called the Negative Temperature Coefficient (NTC). When the temperature is high enough $(\sim 1000 \mathrm{~K})$, due to compression for instance, $\mathrm{H}_{2} \mathrm{O}_{2}$ decomposes into two hydroxyl radicals, which consume the fuel and cause the final ignition to occur. 


\subsection{The effect of the inlet temperature on the auto-ignition process}

This subsection treats the effect of the inlet temperature on the auto-ignition process. This aspect is treated in many works, though in engine conditions not much is found. A particular issue is that on changing the inlet temperature, the charge mass is changed also. This could give wrong indications on the results. To ensure that the same mass is allowed each time, the flow admitted into the engine is kept constant at all times, by controlling the inlet flow rate in the experimental set-up. Soyhan and Mauss [1] have determined the influence of the inlet temperature on the ignition delay, but only at inlet temperatures higher than $700 \mathrm{~K}$. They have determined that a higher initial pressure and inlet temperature result into a lower ignition delay, since this accelerates the overall reaction rate following the Arrhenius equation of kinetics. Kim et al. [16] showed the same temperature dependency for methane at temperatures higher than $1000 \mathrm{~K}$ in a turbulent gaseous jet at a pressure of $40 \mathrm{~atm}$. For a mixture of Primary Reference Fuels, Tanaka et al. [3] observed a decreasing (final) ignition delay on increasing the inlet temperature. The same was observed by Djurisic et al. [17] for benzene and toluene combustion in a shock tube at pressures between 5.4 and $7.4 \mathrm{~atm}$. Gauthier et al. [7] performed stoichiometric n-heptane/air measurements a low-pressure shock tube near 2 and 11 atm at temperatures above $1200 \mathrm{~K}$. Gauthier found like Fieweger et al. [18] that the ignition delay in a shock tube decreased at an increasing inlet temperature. They also found a pronounced NTC region around 700 to $900 \mathrm{~K}$. This phenomenon is found throughout the literature $[\mathbf{7 , 1 9 - 2 5}]$ for $n$-heptane as well as for iso-octane and other heavy hydrocarbons $[\mathbf{2 1 , 2 2 ]}$. From these works, it can be seen that much research is performed on the auto-ignition process, but not as much research is performed on the auto-ignition in an HCCI engine as such. An example for such an investigation is the work of Flowers et al. [26] and Lü et al. [27]. 
This subsection presents the results obtained in this work for the influence of the inlet temperature on the auto-ignition process as defined in the introduction. To begin with, the effect of the inlet temperature on the auto-ignition process is discussed. Figures 1 and 2 show the influence of the equivalence ratio and inlet temperature on respectively the cool flame delays and the final ignition delays. These results are presented in a contour-map since this allows presenting a large quantity of results into a limited number of figures, showing at the same time useful trends. These results show that a higher inlet temperature decreases the cool flame delay, in the same way as it decreases the final ignition delay. A higher inlet temperature accelerates the overall kinetics and thus makes both the ignition delays advance. To have an insight on what happens at much higher inlet temperatures, figure 3 is shown, where the influence of the inlet temperature is calculated by the surrogate mechanism, using the fuel n-heptane at an equivalence ratio of 0.38 and a compression ratio of 10.2. Figure 3 shows that an increase in the inlet temperature decreases the cool flame delay and the final ignition delay simultaneously at about the same gradient, which is confirmed by the literature $[1,3]$. The numerical results in figure 3 , however, show that this only seems to be correct for an inlet temperature region below about $80{ }^{\circ} \mathrm{C}$. At a temperature above this, as figure 3 shows, the final ignition seems to get closer to the cool flame. In other words, the NTC region gets smaller. Following the numerical results, on increasing the inlet temperature, the cool flame would no longer exist and the auto-ignition would occur in one stage. The influence of the inlet temperature on the auto-ignition process can be seen in a different manner, showing the ratio of the heat release at the final ignition and the heat release at the cool flame as a function of the inlet temperature. The ratio $A_{f} / A_{c}$ represents thus the ratio of the fuel burned at the final ignition and at the cool flame. Figure 4 shows that the " $A_{f} / A_{c}$ ratio" remains about constant even for different equivalence ratios and that the inlet temperature does not effect the distribution (over the cool flame and the final ignition) of the consumed fuel. 


\subsection{The effect of the equivalence ratio on the auto-ignition process}

The influence of the equivalence ratio on the ignition delays is also presented in figures 1 and 2. Before these results are analysed, a more profound discussion about the effect of the equivalence ratio on the auto-ignition process is performed. This subsection treats the influence that the equivalence ratio could have on the auto-ignition process. The equivalence ratio is one of the most important effects, since it is the primary parameter that determines the supplied energy. Then again, the discussion about the equivalence ratio is omni-present in the literature, as shows the literature in the introduction. However, more understanding is needed regarding the effect of the equivalence ratio on the auto-ignition process as a whole. Gauthier et al. [7] found that an increase in the equivalence ratio enhanced auto-ignition. A higher equivalence ratio provides for more fuel to burn and more energy to be released. This is also observed by many others $[\mathbf{3 , 2 8 , 2 9 ]}$. The completeness of the combustion is also influenced by the equivalence ratio as is found by Shiga et al. [30], investigating compressed-natural-gas direct-injection stratified combustion in a rapid compression machine. Shiga et al. found that a higher equivalence ratio for a homogeneous mixture results into a higher combustion efficiency. Just the opposite, however, is observed by MacNamara and Simmie [31] who state that the ignition delay of the combustion of pyridine and pyrrole shows negative oxygen concentration dependence. This means that the lower the oxygen content - the higher the equivalence ratio - the higher the ignition delay is. Lewis and Von Elbe [32] observed this same dependency. Apparently there seems to be a contradiction in the literature with respect to the influence of the equivalence ratio on the ignition delays. Aichlmayr et al. [33] also observed this contradiction in their work. They explained this contradiction by performing

adiabatic calculations. They state that the charges do not reach the same temperature following the adiabatic compression. Mixture specific heats increase with equivalence ratio. 
Consequently for equal compression ratios, a lean mixture will have a greater temperature following compression than a rich mixture, and therefore a shorter ignition time [33]. Aichlmayr et al. explain this phenomenon as compressive heating. This suggests that two aspects compete with each other on increasing the equivalence ratio: the energy supplied and the compressive heating. To visualize this effect qualitatively, three numerical cases are considered, by means of the kinetic mechanism. The kinetic mechanism calculations allow separating the effects of the equivalence ratio. In the first case the gas temperature is calculated in an engine, without reaction, on increasing the equivalence ratio of the fuel isooctane at a compression ratio of 8 (the compression ratio is kept too low to avoid reaction). In the second case, the gas temperature is calculated in an engine, without reaction, on increasing the heat capacity by choosing different inert gases with different heat capacities. In the third case, a simulation is performed in a constant volume environment (to cancel out compressive heating) by calculating the gas temperature on increasing the equivalence ratio. Figures 5,6 and 7 present the results. Figure 5 shows that a higher equivalence ratio, increasing thereby the heat capacity, results into a lower gas temperature. Figure 6 shows that on increasing the heat capacity $\left(\mathrm{C}_{\mathrm{p}, \mathrm{CO} 2}>\mathrm{C}_{\mathrm{p}, \mathrm{O} 2}>\mathrm{C}_{\mathrm{p}, \mathrm{N} 2}\right)$, indeed the gas temperature is lower. These two figures show that increasing the heat capacity (both due to the use of a compound with a higher heat capacity and by increasing the equivalence ratio of a fuel) results into decreasing the gas temperature. Figure 7 shows that, obviously, a higher equivalence ratio in a constant volume reactor increases the gas temperature. These two factors compete with each other. Depending on the burn rate of the fuel one factor prevails over the other. If the burn rate of a fuel is high enough it overcomes the effect of the compressive heating and vice versa. An example of a fuel that has some difficulty in overcoming the compressive heating, for its relatively low burn rate, is iso-octane. In figure 8 , the cool flame delays and the final ignition delays for isooctane are shown as a function of the equivalence ratio. The compression ratio is 13.5 and the 
inlet temperature is $70{ }^{\circ} \mathrm{C}$. For the cool flame delays, the effect of compressive heating is quite visible. Even the final ignition delays, seem to decrease less at higher equivalence ratios, suggesting that the compressive heating becomes important at that point. Having discussed the two contradicting effects of the equivalence ratio, the effect of the equivalence ratio on the experimental ignition delays, which is presented in figures 1 and 2, can now be discussed. Figures 1 and 2 show that the equivalence ratio seems to decrease both the cool flame delay and the final ignition delay, though more pronouncedly the latter, as found in the literature as well $[28,29]$. A higher equivalence ratio adds more fuel to the inlet mixture, thereby increasing the rate of reaction between the hydroxyl radical and the fuel. This leads to more fuel consumption and advancement of the ignition delays. This is confirmed by the heat release. Figure 9 shows the relative total heat release as a function of the equivalence ratio. The relative total heat release is with respect to the total heat release at an equivalence ratio of 0.23. Figure 9 shows indeed that an increasing equivalence ratio increases the total amount of heat release. Figure 1 shows furthermore that it seems that at higher equivalence ratios the influence of the equivalence ratio becomes less for the cool flame. There is another aspect to be taken into account, besides the energy supply by the fuel. More fuel decreases the heat capacity of the mixture. A decreasing heat capacity means an increase of the poly-entropic constant. This means that during the compression, due to the compressive heating, the gas temperature is lower already before the cool flame. This is represented by figure 10, showing the gas temperatures for equivalence ratios of respectively 0.4 and 0.8 with a compression ratio of 10.2 , an inlet temperature of $70{ }^{\circ} \mathrm{C}$ and n-heptane as the fuel. Apparently, the gas temperature at a higher equivalence ratio is lower, causing the cool flame to be delayed. However, having more fuel to react, the gas temperature is higher after the cool flame, the NTC delay shorter and thus the final ignition is advanced. The compressive heating is easily overcome when the burn rate of the fuel is high enough as is the case of most of the 
conditions studied, since there an increasing equivalence ratio results into a decreasing ignition delay. Most of the fuels studied contain enough n-heptane, which has a relatively high burn rate. Therefore most of the fuels show a decreasing tendency of the cool flame on increasing the equivalence ratio. However, beyond a certain equivalence ratio, depending on amongst others the burn rate of the fuel, this is no longer overcome and a further increase of the fuel quantity will delay even the final ignition. Figure 11 illustrates this effect, using the surrogate mechanism. The inlet temperature is $70{ }^{\circ} \mathrm{C}$, the compression ratio is 10 and the fuel is n-heptane. The surrogate mechanism was not validated experimentally at an equivalence ratio higher than 0.64 . This means that beyond this value the calculations would not be reliable, but it should certainly give the right tendency. No evident indication was spotted during the validations that this surrogate mechanism showed deviating values approaching the equivalence ratio of 0.64 , so that it is not likely that it should deviate a lot afterwards. This justifies using this mechanism for extrapolation estimations. The experimental findings in the experiments and the numerical ones, obtained from the kinetic mechanism, suggest that these two results support each other.

At an equivalence ratio around 1.0, it can be seen that the final ignition begins to increase on increasing the equivalence ratio. The simulation shows also that at an equivalence ratio of around 0.9 , it seems that the two-stage combustion turns into a one-stage combustion. This means that the conditions are such that the NTC region does not has the time to be present at equivalence ratios higher than 0.9 . This can be seen, in figure 12 , by the relatively late formation of formaldehyde and its immediate consumption at an equivalence ratio of 1.1. At an equivalence ratio of 0.4 , the formaldehyde is formed earlier and has a certain residence time, before it is consumed. The relatively short existence of formaldehyde at an equivalence ratio of 1.1 shows that there the combustion proceeds in one stage, contrary to the two-stage combustion at an equivalence ratio of 0.4 . The late formation of formaldehyde confirms the 
higher ignition delay at an equivalence ratio of 1.1. This does not contradict the effect of compressive heating. The same conclusions can be drawn for the residence time of $\mathrm{H}_{2} \mathrm{O}_{2}$, which is a typical NTC product.

\subsection{The effect of the compression ratio on the auto-ignition process}

The influence of the compression ratio on the ignition delay seems to gain less interest in the literature than the ones discussed previously, because of the difficulty of implementing a variation of the compression ratio in an engine with the present technological tools. Therefore, only few works consider the effect of the compression ratio on the auto-ignition process, either directly by varying the cylinder volume [33-35] or indirectly by variable valve timing [36]. Nonetheless, the effect of the compression ratio should not be neglected, since it could be one of the key parameter in the design of an engine. In a miniature free-piston HCCI engine, Aichlmayr et al. [33] observed that an increase in the compression ratio resulted into a decrease of the ignition delay. The same was observed in a Diesel engine $[\mathbf{3 4 , 3 5}]$. For a same equivalence ratio, a higher compression ratio causes a smaller end-volume in the cylinder before ignition at a higher pressure and temperature, resulting in an overall higher concentration of all the species. This higher concentration causes the overall reaction rate to increase and thus the ignition delay to decrease. The influence of the compression ratio has been studied for two fuels: n-heptane and "60 vol\% n-heptane / 40 vol\% iso-octane". Figure 13 shows the influence of the compression ratio on the ignition delays for these two fuels at an equivalence ratio of 0.33 and an inlet temperature of $70{ }^{\circ} \mathrm{C}$. From figure 13 , it appears that the compression ratio has a large influence on the cool flame delays and on the final ignition delays. The compression ratio seems to have two effects. On one hand, a higher compression ratio increases the concentration of all the species and increases also the peak temperature and the overall reactivity. This causes the ignition delays to advance. Again, the kinetic 
mechanism can be used to separate the effects that are due to a change in the compression ratio. Figure 14 shows that the gas temperature of the cylinder increases when the compression ratio is increased ( 8 and 12), using the $0 \mathrm{D}$ engine code, with no fuel (and thus no residual gases are taken into account for this calculation) and an inlet temperature of $70{ }^{\circ} \mathrm{C}$. When looking at the temperatures, in figure 14 , one can see that the pressure is higher at higher compression ratios, explaining the higher reactivity. On the other hand, another effect of the compression ratio plays an important role: the fraction of the residual gases. The residual gases can have two important effects. The fraction of the residual gas $(f)$ is a reciprocal function of the compression ratio $(\varepsilon)$, expressed by the following approximation [15]:

$$
f=\frac{T_{\text {inlet }}}{\left(\frac{P_{I V C} r_{E}}{P_{E} r_{I V C}} \varepsilon-\frac{C_{p, R}}{C_{p, I V C}}\left(\frac{P_{I V C}}{P_{E}}\right)^{\left(\frac{\bar{T}}{\bar{T}}\right)}\right) T_{E}+\left(\frac{C_{p, R}}{C_{p, I V C}}-1\right) T_{0}+T_{\text {inlet }}}
$$

This equation results from mass and energy balances made at Inlet Valve Closing (IVC) at the Exhaust (E) and for the Residual gases (R). The residual gas has a higher temperature than the inlet temperature and therefore the overall kinetics are higher than would be the case if no residual gases were present. A higher compression ratio results into a lower residual gas fraction. Therefore the effect of the residual gas temperature is less at higher compression ratios. So, on increasing the compression ratio, the overall reactivity does increase, but more slowly every time the compression ratio increases. This effect can be seen in figure 13 , where the ignition delays decrease at a slower rate on increasing the compression ratio. The second effect of the residual gases is its composition. True, at a higher compression ratio, the residual gas fraction is smaller. However, due to the higher compression ratio, the overall concentrations are higher and also those of the residual gas. It could be that the residual gas contains chemically active species, of which the concentration increases at a higher 
compression ratio. Depending on the competitivity between this concentration increase and the decrease of the residual gas fraction, these chemically active species can affect the autoignition process in a way that might compensate or reinforce the increasing overall reactivity of the auto-ignition. Figure 15 shows the behavior of the ignition delay on increasing further the compression ratio, beyond 14, using the surrogate mechanism. Indeed, it seems that the gradient (illustrated by striped lines) of the ignition delay decreases at higher compression ratios. This is due to the effect of the residual gases, discussed previously.

\section{Conclusions}

The inlet temperature, the equivalence ratio and the compression ratio were varied and their influence on the auto-ignition process analyzed. The inlet temperature was changed from 25 to $70{ }^{\circ} \mathrm{C}$ and the equivalence ratio from 0.18 to 0.41 , while the compression ratio varied from 6 to 13,5 . The fuels that were investigated were PRF40 and n-heptane. The influence of the inlet temperature has shown a clear promoting effect on the ignition delays. The heat release distribution did not seem to be affected by the inlet temperature. This could imply that the inlet temperature is a parameter than can be used to influence the auto-ignition process, without altering the energetic content. The influence of the inlet temperature, however, appeared to have the smallest effect, though significant, of the three parameters investigated. The influence of the equivalence ratio has shown two distinct effects. One effect is the promoting effect on the ignition delay, due to the higher energy supply. The other effect is the compressive heating due to the increase of the heat capacity of the mixture. These two effects compete with each other and it seemed that as long as the burn rate of the fuel is high enough, the effect of the compressive heating is overcome. This effect seems also to be represented by the surrogate mechanism. The heat release seemed to be effected quite clearly by the equivalence ratio, showing that on increasing the equivalence ratio, the heat release the 
increases as well. Generally speaking, it can be said that the equivalence ratio can be used to decrease the ignition delays at HCCI conditions, having a great influence on the heat release. This makes the equivalence ratio a suitable candidate for the HCCI control. The compression ratio also appears to have two effects. The obvious effect is advancing the ignition delay, due to higher overall reactivity, pressure, temperature and overall concentrations. The other effect is the residual gas fraction. A higher compression ratio results into a lower residual gas fraction and thus a lower thermal effect of the residual gas. This effect seems to slow done the increasing overall reactivity. The surrogate mechanism also represented this contradiction quite satisfactory, which means that the initial conditions, taking into account the effect of the residual gas, were calibrated decently. On increasing the compression ratio, the residual gas can have another indirect effect. The higher compression ratio causes the overall concentrations to increase, including the species that are present in the residual gas. Moreover, the residual gas can contain several chemically active species, of which the concentration increases. Depending on the competitivity between this concentration increase and the decrease of the residual gas fraction, these chemically active species can influence the auto-ignition process in a way that might compensate or reinforce the increasing overall reactivity. These findings and observations have provided an overall insight of the autoignition process influenced by important engine parameters. Furthermore, the use of the kinetic mechanism has provided deeper insight of the influence of the parameters on the autoignition process, which can be used for auto-ignition control purposes. 


\section{References}

1 H.S. Soyhan, F. Mauss, C. Sorusbay, Chemical Kinetic Modeling of Combustion in Internal Combustion Engines Using Reduced Chemistry, Comb. Sc. Tech., 174 (2002) 73-91.

2 M. Sjöberg, J.E. Dec, An investigation into lowest acceptable combustion temperatures for hydrocarbon fuels in HCCI engines, Proc. Comb. Inst., 30 (2005) 2719-2726.

3 S. Tanaka, F. Ayala, J.C. Keck, J.B. Heywood, Two-stage ignition in HCCI combustion and HCCI control by fuels and additives, Comb. Flame, 132 (2003) 219239.

4 J.P. Szybist, A.L. Boehman, D.C. Haworth, H. Koga, Premixed ignition behavior of alternative diesel fuel-relevant compounds in a motored engine experiment, Comb. Flame, 149 (2007) 112-128.

5 T. Faravelli, P. Gaffuri, E. Ranzi, J.F. Griffiths, Detailed thermokinetic modelling of alkane autoignition as a tool for the optimization of performance of internal combustion engines, Fuel, 77 (1998) 147-155.

6 M. Sjöberg, J.E. Dec, Comparing late-cycle autoignition stability for single- and twostage ignition fuels in HCCI engines, Proc. Comb. Inst. 31 (2007) 2895-2902.

7 B.M. Gauthier, D.F. Davidson, R.K. Hanson, Shock tube determination of ignition delay times in full-blend and surrogate fuel mixtures, Comb. Flame, 139 (2004) 300311.

8 A. Roubaud, R. Minetti, L.R. Sochet, Oxidation and Combustion of Low Alkylbenzenes at High Pressure: Comparative Reactivity and Auto-Ignition, Comb. Flame, 121 (2000) 535-541. 
9 J.P. Szybist, B.G. Bunting, Cetane Number and Engine Speed Effects on Diesel HCCI Performance and Emissions, SAE (2005) 2005-01-3723.

10 P. Maigaard, F. Mauss, M. Kraft, Homogeneous Charge Compression Ignition Engine: A Simulation Study on the Effects of Inhomogeneities, ASME J. Eng. Gas Turb. Power, 125 (2003) 466-471.

11 S.H. Kang, S.W. Baek, J.H. Choi, Autoigntion of sprays in a cylindrical combustor, International Journal of Heat and Mass Transfer, 44 (2001) 2413-2422.

12 R. Chen, N. Milovanovic, A computational study into effect of exhaust gas recycling on homogeneous charge compression ignition combustion in internal combustion engines fuelled with methane, International Journal of Thermal Science, 41 (2002) 805-813.

13 M. Furutani, M. Kono, M. Kojima, M. Nose, Y. Ohta, Chemical species histories up to ignition in premixed-compression-ignition natural-gas engine, The fifth International Symposium on Diagnostics and Modeling of Combustion in Internal Combustion Engines, Comodia (2001) 461-466.

14 H.J. Curran, W.J. Pitz, C.K. Westbrook, P. Gaffuri, W.R. Leppard, Autoignition Chemistry in a Motored Engine: An Experimental and Kinetic Modeling study, International Symposium on Combustion, 26 (1996) 2669-2677.

15 H. Machrafi, Development and experimental validation of kinetic schemes for hydrocarbon mixtures for HCCI applications. Investigation of the auto-ignition process and the application to internal combustion engines, $\mathrm{PhD}$ thesis, University of Paris 6 (UPMC), Paris, 2006.

16 S.K. Kim, Y. Yu, J. Ahn, Y-M. Kim, Numerical investigation of the autoignition of turbulent gaseous jets in a high-pressure environment using the multiple-RIF model, Fuel, 83 (2004) 375-386. 
17 Z.M. Djurisic, A.V. Joshi, H. Wang, Detailed Kinetic Modeling of Benzene and Toluene Combustion, Second Joint Meeting of the U.S. Sections of the Combustion Institute, Oakland, (2001) 8p.

18 K. Fieweger, R. Blumenthal, G. Adomeit, Self-ignition of S.I. Engine Model Fuels: A Shock Tube Investigation at High Pressure, Comb. Flame, 109 (1997) 599-619.

19 J. Warnatz, Resolution of Gas Phase and Surface Combustion Chemistry into Elementary Reactions, Int. Symp. on Comb., 24 (1992) 553-579.

20 H.J. Curran, W.J. Pitz, C.K. Westbrook, C.V. Callahan, F.L. Dryer, Oxidation of automotive primary reference fuels at elevated pressures, Lawrence Livermore National Laboratory, Livermore, UCRL-JC-133410, Int. Symp. on Comb., 27 (1998) $379-387$.

21 A. Ciajolo, A. D'Anna, Controlling Steps in the Low-Temperature Oxidation of nHeptane and iso-Octane, Comb. Flame, 112 (1998) 617-622.

22 S. Wang, D.L. Miller, N.P. Cernansky, H.J. Curran, W.J. Pitz, C.K. Westbrook, A Flow Reactor Study of Neopentane Oxidation at 8 Atmospheres: Experiments and Modeling, Comb. Flame, 118 (1999) 415-430.

23 H.J. Curran, P. Gaffuri, W.J. Pitz, C.K. Westbrook, A Comprehensive Modeling Study of n-Heptane Oxidation, Comb. Flame, 114 (1998) 149-177.

24 R. Minetti, M. Carlier, M. Ribaucour, E. Therssen, L.R. Sochet, A Rapid Compression Machine Investigation of Oxidation and Auto-Ignition of n-Heptane: Measurements and Modeling, Comb. Flame, 102 (1995) 298-309.

25 E. Ranzi, T. Faravelli, P. Gaffuri, A. Sogaro, A. D'anna, A. Ciajolo, A Wide-Range Modeling Study of Iso-Octane Oxidation, Comb. Flame, 108 (1997) 24-42.

26 D. Flowers, S.M. Aceves, J. Marinez-Frias, J.R. Smith, M. Au, J. Girard et al., Operation of a four-cylinder 1.9L propane fueled homogeneous charge compression 
ignition engine : basic operating characteristics and cylinder-to-cylinder effects, SAE (2001) 2001-01-1895.

27 X. Lü, W. Chen, Z.Huang, A fundamental study on the control of the HCCI combustion and emissions by fuel design concept combined with controllable EGR. Part 1. The basic characteristics of the HCCI combustion, Fuel, 84 (2005) 1074-1083.

28 D. Flowers, S. Aceves, R. Smith, J.Torres, J. Girard, R. Dibble, HCCI in a CFR Engine: Experiments and Detailed Kinetic Modeling, SAE World Congress (2000) 2000-01-0328.

29 D. Flowers, S. Aceves, C.K. Westbrook, R. Smith, R. Dibble, Detailed Chemical Kinetic Simulation of Natural Gas HCCI Combustion: Gas Composition Effects and Investigation of Control Strategies, J. Eng. Gas Turb Power, 123 (2001) 433.

30 S. Shiga, S. Ozone, H.T.C. Machacon, T. Karasawa, H. Nakamura, T. Ueda et al., A study of the Combustion and Emission Characteristics of Compressed-Natural-Gas Direct-Injection Stratified Combustion Using a Rapid-Compression-Machine, Comb. Flame, 129 (2002) 1-10.

31 J.P. MacNamara, J.M. Simmie, The high temperature oxidation of pyrrole and pyridine; ignition delay times measured behind reflected shock waves, Comb. Flame, 133 (2001) 231-239.

32 B. Lewis, G. Von Elbe, Combustion, Flames and Explosions of Gases, $3^{\text {rd }}$ Ed., Academic Press, New York, 1987.

33 H.T. Aichlmayr, D.B. Kittelson, M.R. Zachariah, Miniature free-piston homogeneous charge compression ignition engine-compressor concept - Part II: modeling HCCI combustion in small scales with detailed homogeneous gas phase chemical kinetics, Chem. Eng. Sc., 57 (2002) 4173-4186. 
34 A. Parlak, H. Yasar, B. Sahin, Performance and exhaust emission characteristics of a lower compression ratio LHR Diesel engine, Energy Convers. Manage, 44 (2003) 163175.

35 M.Y.E. Selim, M.S. Radwan, S.M.S. Elfeky, Combustion of jojoba methyl ester in an indirect injection diesel engine, Renew. Energy, 28 (2003) 1401-1420.

36 G.M. Shaver, J.C. Gerdes, M.J. Roelle, P.A. Caton, C.F. Edwards, Dynamic Modeling of Residual-Affected Homogeneous Charge Compression Ignition Engines with Variable Valve Actuation, Journal of Dynamic Systems, Measurement and Control 127 (2005) 374-381. 


\section{Figure captions}

Figure 1: Ignition delays for the cool flame as a function of the inlet temperature and equivalence ratio, with a compression ratio of 10.2 and n-heptane as the fuel

Figure 2: Ignition delays for the final ignition as a function of the inlet temperature and equivalence ratio, with a compression ratio of 10.2 and n-heptane as the fuel

Figure 3: Ignition delays as a function of the inlet temperature at a compression ratio of 10,2, an equivalence ratio of $0.38 \mathrm{~K}$ using $\mathrm{n}$-heptane as the fuel

Figure 4: Heat release ratio of the final ignition $\left(A_{f}\right)$ and the cool flame $\left(A_{c}\right)$ at an equivalence ratio of 0.3 and 0.4 , a compression ratio of 10.2 , using n-heptane as the fuel, varying the inlet temperature

Figure 5: Influence of the equivalence ratio on the calculated gas temperature with an inlet temperature of $343 \mathrm{~K}$, a compression ratio of 8 and iso-octane as the fuel

Figure 6: Influence of heat capacity on the calculated gas temperature by varying the type of inert gas with different heat capacities with inlet temperature of $343 \mathrm{~K}$ and compression ratio of 14

Figure 7: Influence of equivalence ratio on the calculated gas temperature in a constant volume reactor with an initial temperature of $660 \mathrm{~K}$ and an initial pressure of 8 bar and nheptane as the fuel

Figure 8: The cool flame delays and the final ignition delays as a function of the equivalence ratio at an inlet temperature of $70{ }^{\circ} \mathrm{C}$, a compression ratio of 13.5 and iso-octane as the fuel

Figure 9: Relative total heat release (with respect to the total heat release at equivalence ratio 0.23 ) at an inlet temperature of $70{ }^{\circ} \mathrm{C}$, a compression ratio of 10,2 , using $\mathrm{n}$-heptane as the fuel, varying the equivalence ratio

Figure 10: The gas temperatures for equivalence ratios of respectively 0,4 and 0,8 with a compression ratio of 10.2 , an inlet temperature of $70^{\circ} \mathrm{C}$ and $\mathrm{n}$-heptane as the fuel 
Figure 11: Ignition delays as a function of equivalence ratio at a compression ratio of 10, an inlet temperature of $70{ }^{\circ} \mathrm{C}$ using n-heptane as the fuel

Figure 12: Species profile of $\mathrm{CH}_{2} \mathrm{O}$ and $\mathrm{H}_{2} \mathrm{O}_{2}$ at equivalence ratios 0.4 and 1.1 at a compression ratio of 10.2 , an inlet temperature of $70{ }^{\circ} \mathrm{C}$ using n-heptane as the fuel

Figure 13: Influence compression ratio on the ignition delays at an inlet temperature of $70{ }^{\circ} \mathrm{C}$, an equivalence ratio of 0.33 comparing the fuels n-heptane and PRF40

Figure 14: The gas temperature as a function of the compression ratio at an inlet temperature of $70^{\circ} \mathrm{C}$

Figure 15: The cool flame and final ignition delays as a function of the compression ratio, at an inlet temperature of $70{ }^{\circ} \mathrm{C}$, an equivalence ratio of 0.41 and n-heptane as the fuel 


\section{Figures}

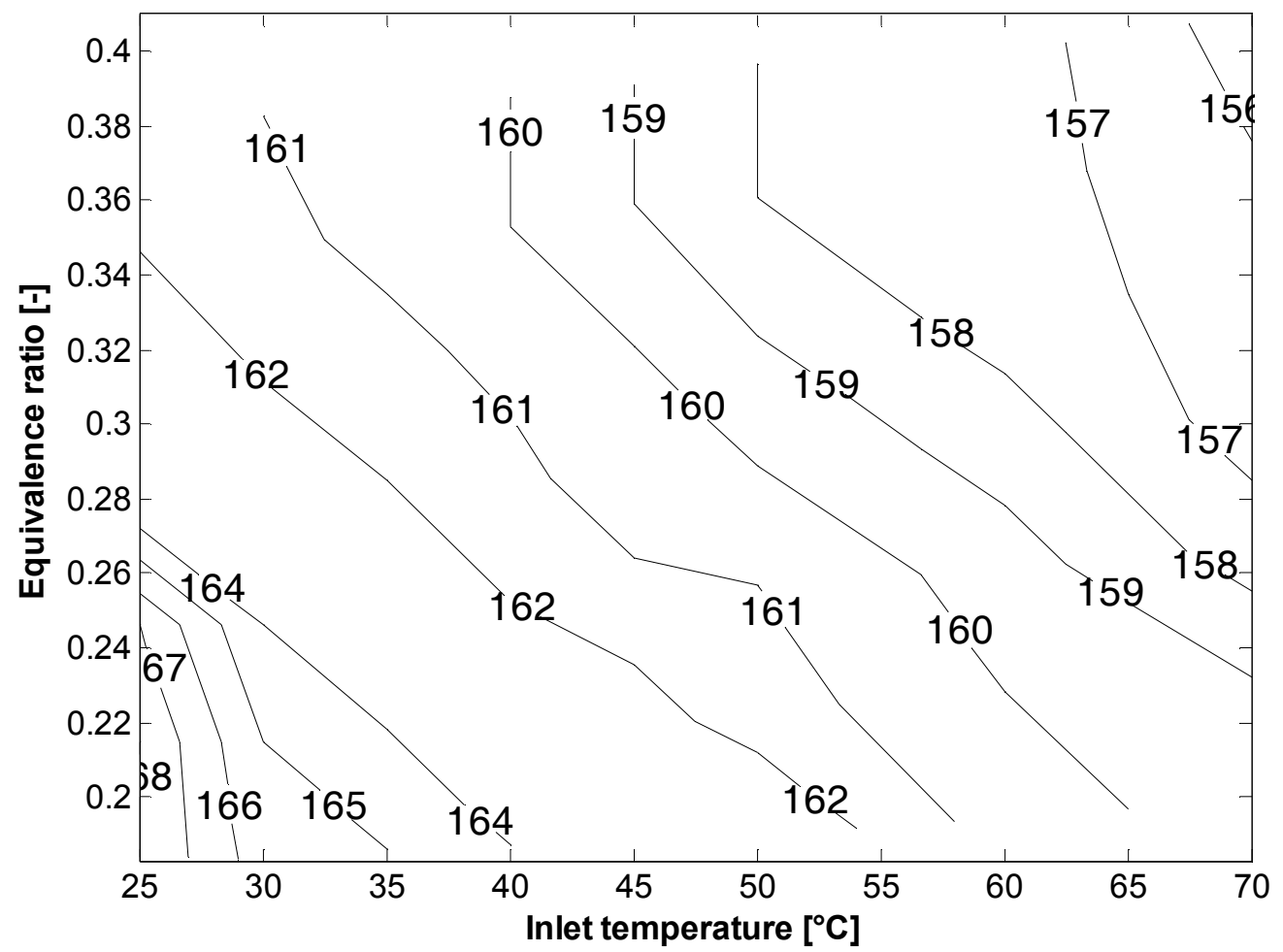

Figure 1: Ignition delays for the cool flame as a function of the inlet temperature and equivalence ratio, with a compression ratio of 10.2 and n-heptane as the fuel 


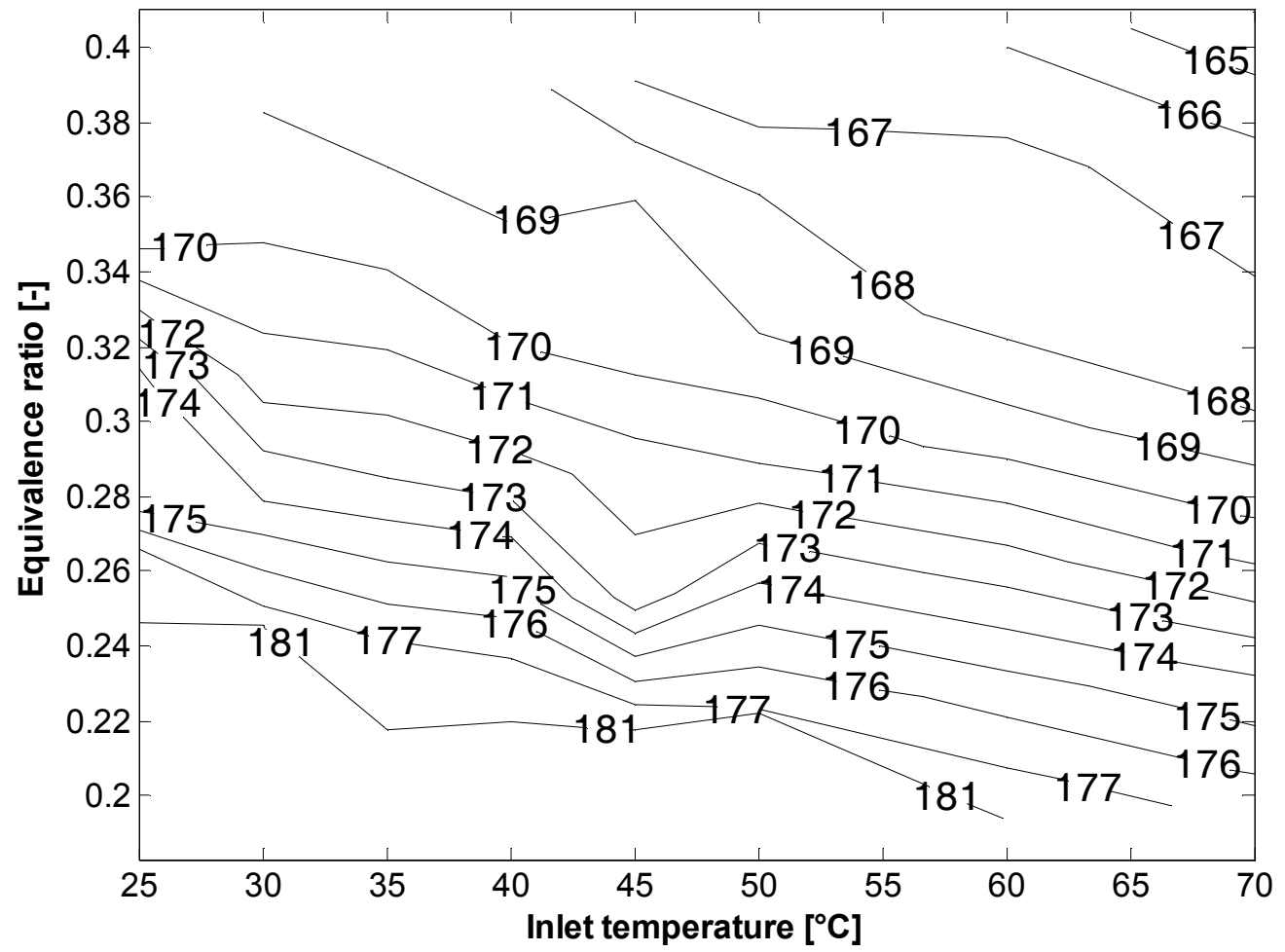

Figure 2: Ignition delays for the final ignition as a function of the inlet temperature and equivalence ratio, with a compression ratio of 10.2 and n-heptane as the fuel 


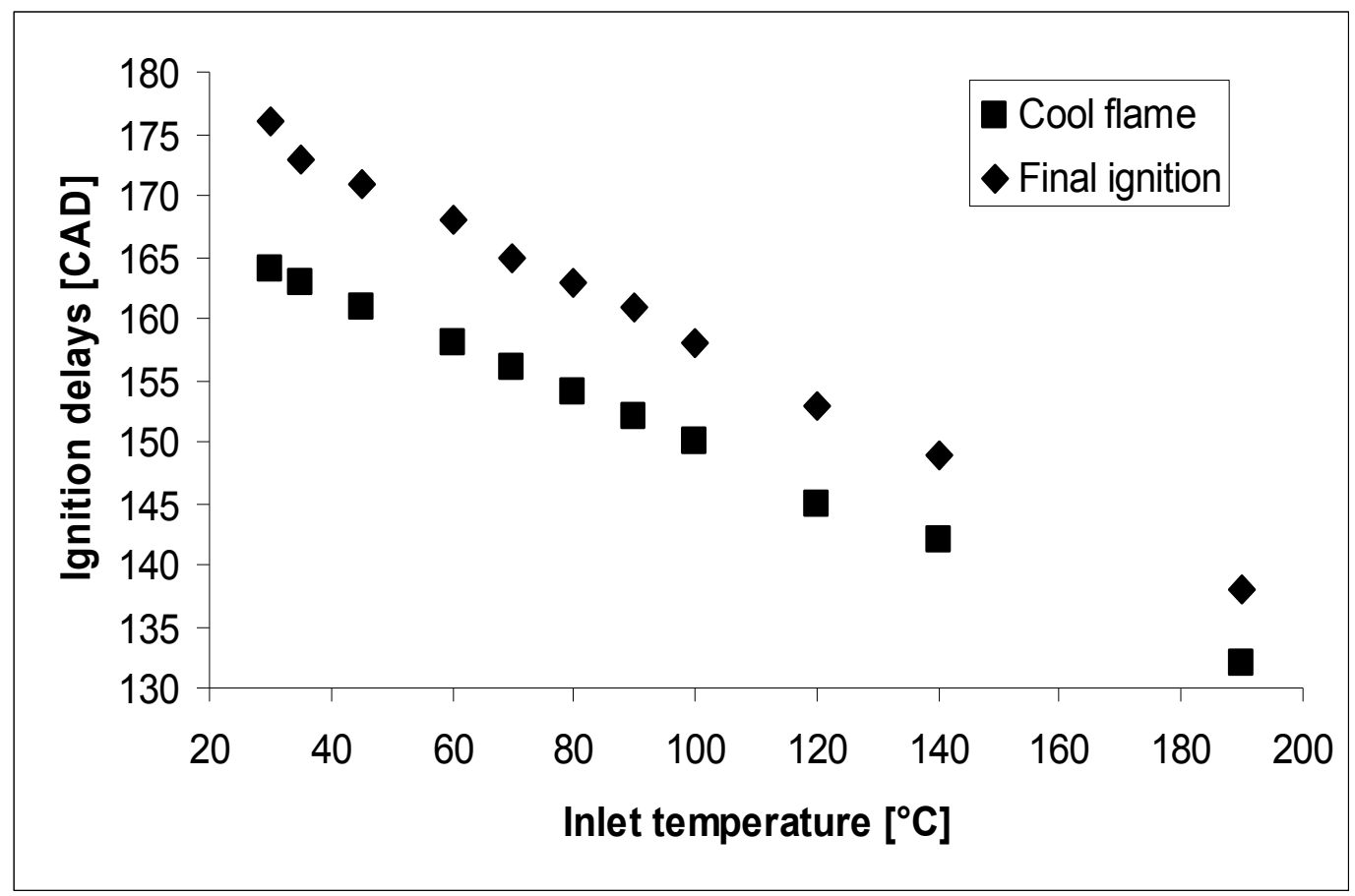

Figure 3: Ignition delays as a function of the inlet temperature at a compression ratio of 10,2, an equivalence ratio of $0.38 \mathrm{~K}$ using $n$-heptane as the fuel 


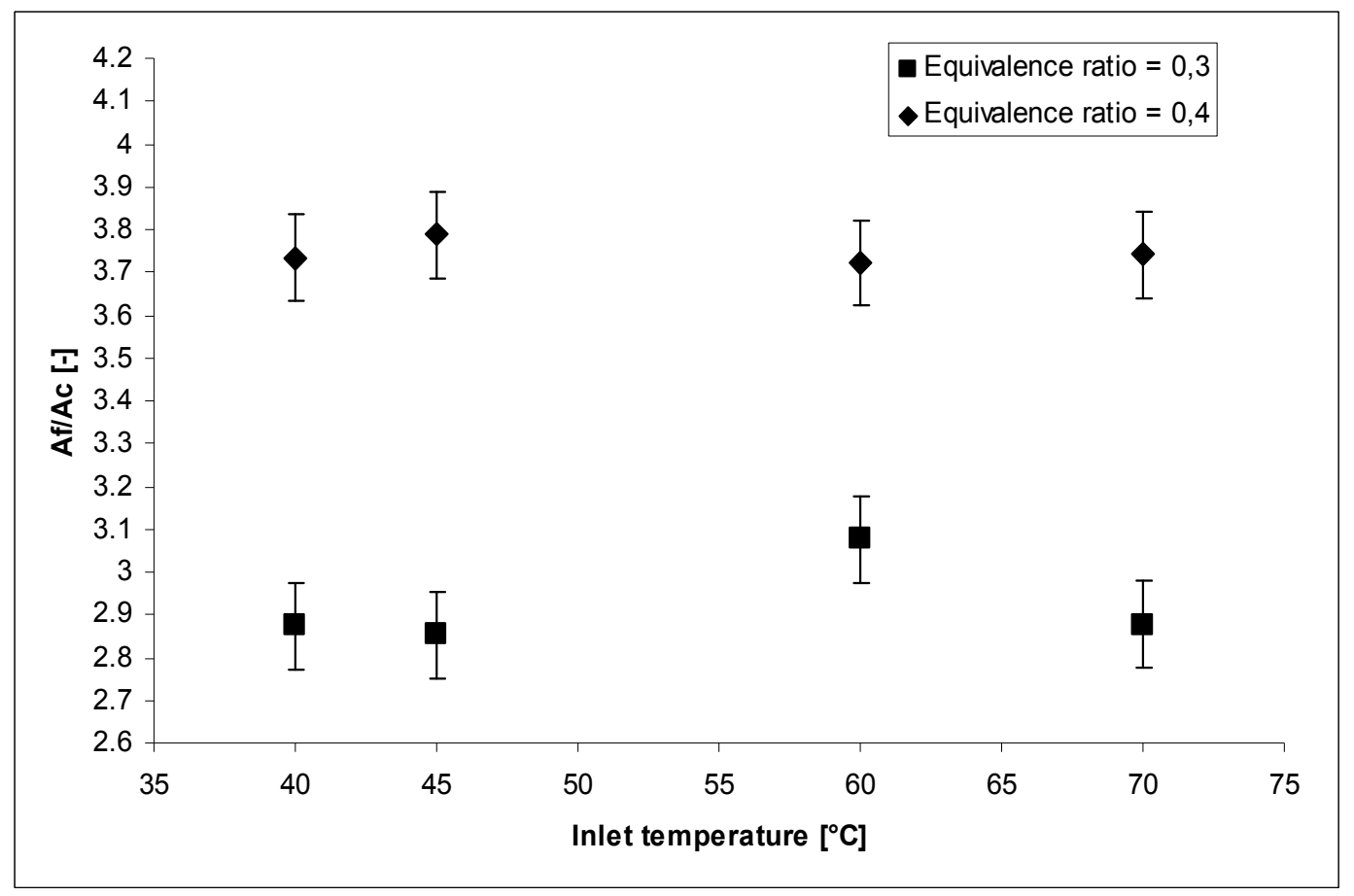

Figure 4: Heat release ratio of the final ignition $\left(A_{f}\right)$ and the cool flame $\left(A_{c}\right)$ at an equivalence ratio of 0.3 and 0.4, a compression ratio of 10.2, using n-heptane as the fuel, varying the inlet temperature 




Figure 5: Influence of the equivalence ratio on the calculated gas temperature with an inlet temperature of $343 \mathrm{~K}$, a compression ratio of 8 and iso-octane as the fuel 


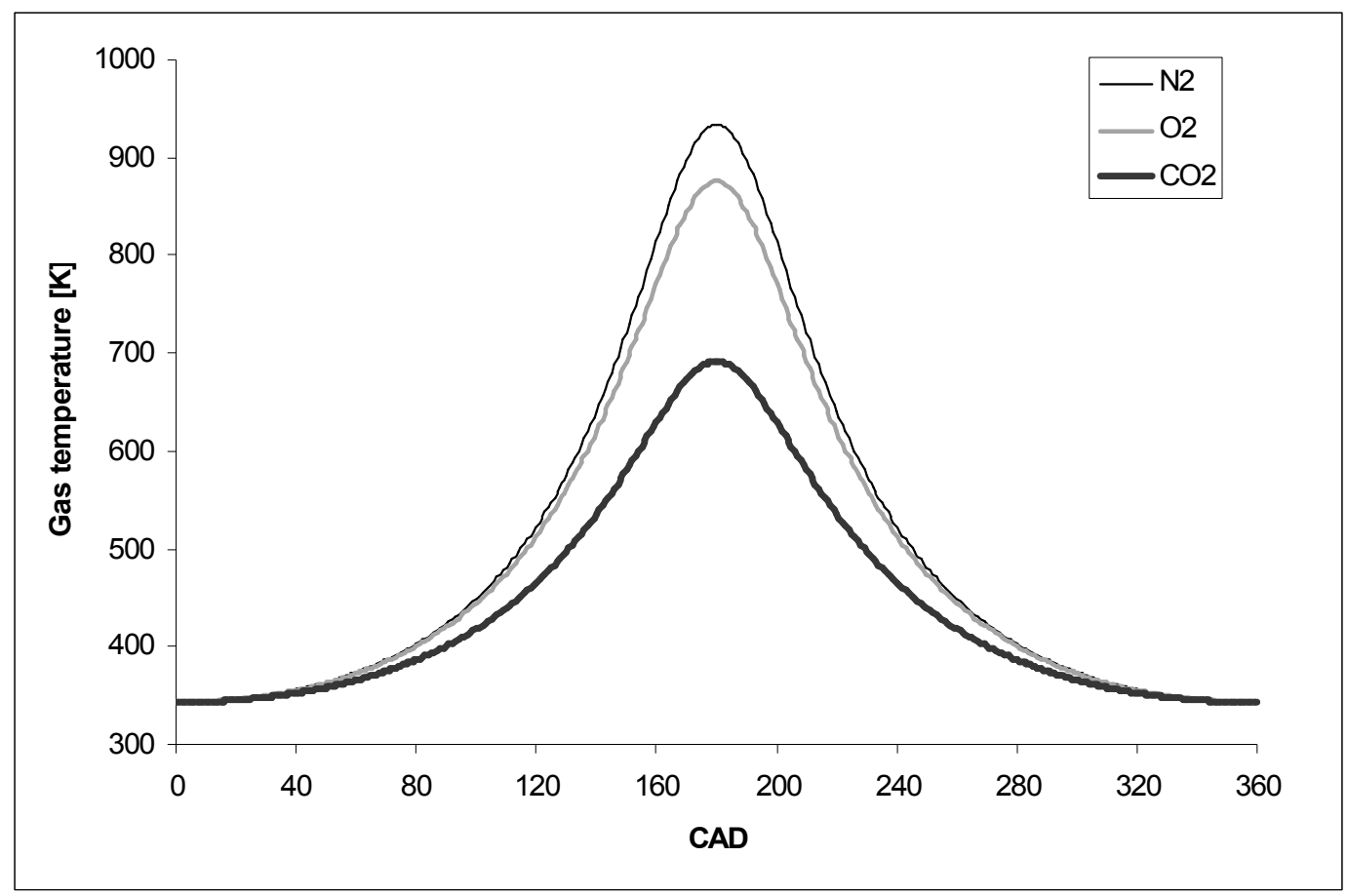

Figure 6: Influence of heat capacity on the calculated gas temperature by varying the type of inert gas with different heat capacities with inlet temperature of $343 \mathrm{~K}$ and compression ratio of 14 


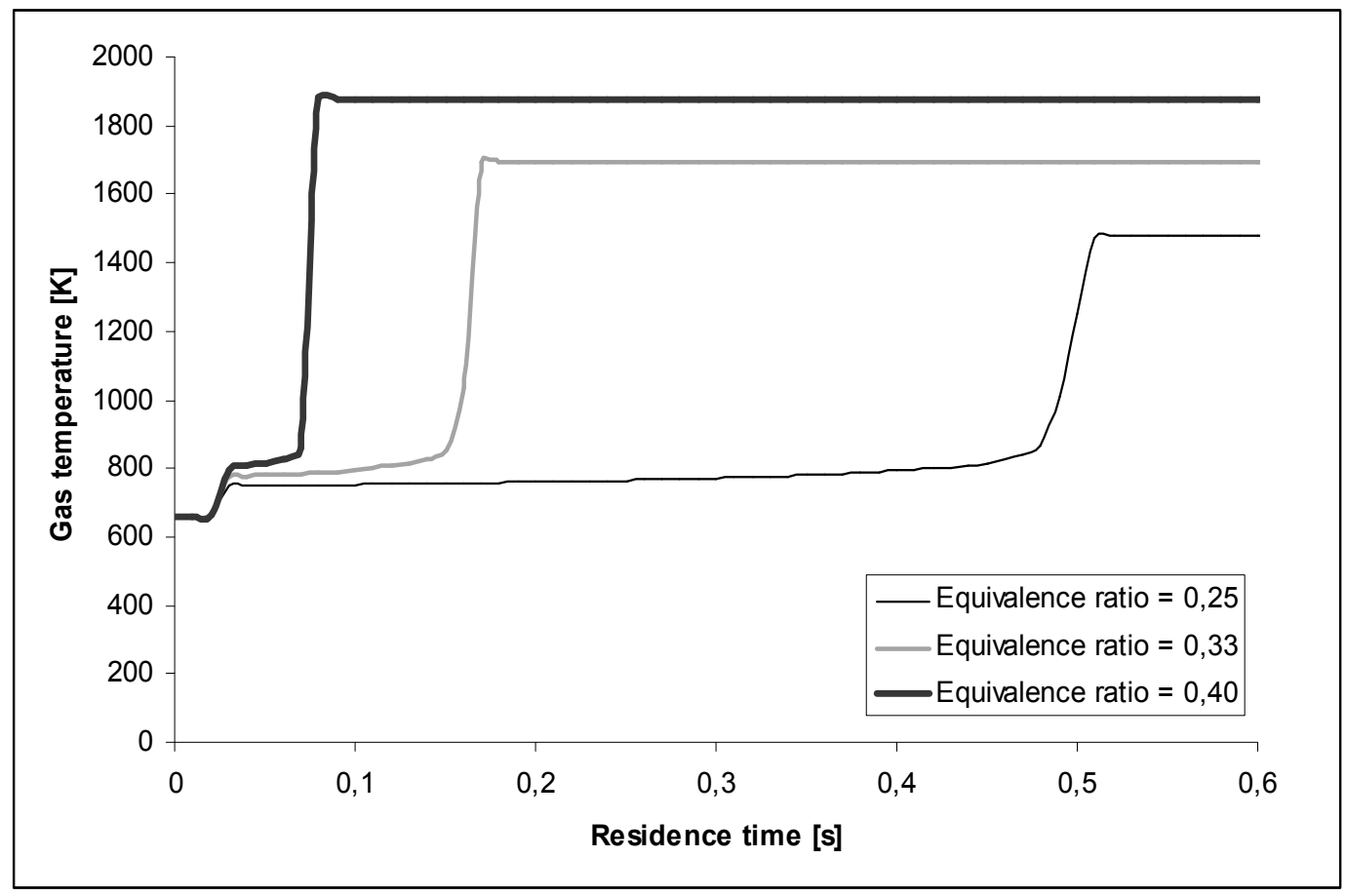

Figure 7: Influence of equivalence ratio on the calculated gas temperature in a constant volume reactor with an initial temperature of $660 \mathrm{~K}$ and an initial pressure of 8 bar and $n$ heptane as the fuel 


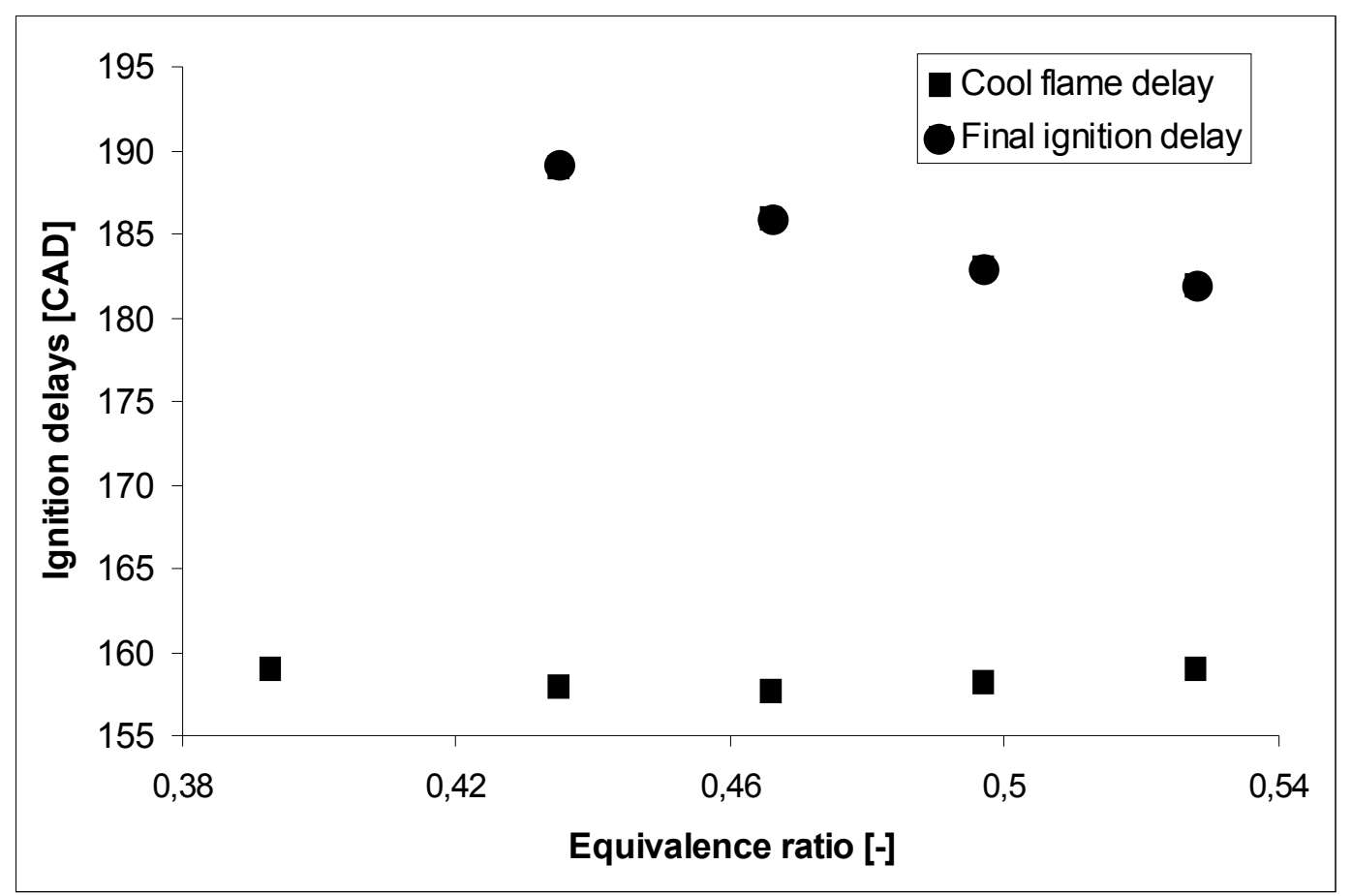

Figure 8: The cool flame delays and the final ignition delays as a function of the equivalence ratio at an inlet temperature of $70^{\circ} \mathrm{C}$, a compression ratio of 13.5 and iso-octane as the fuel 


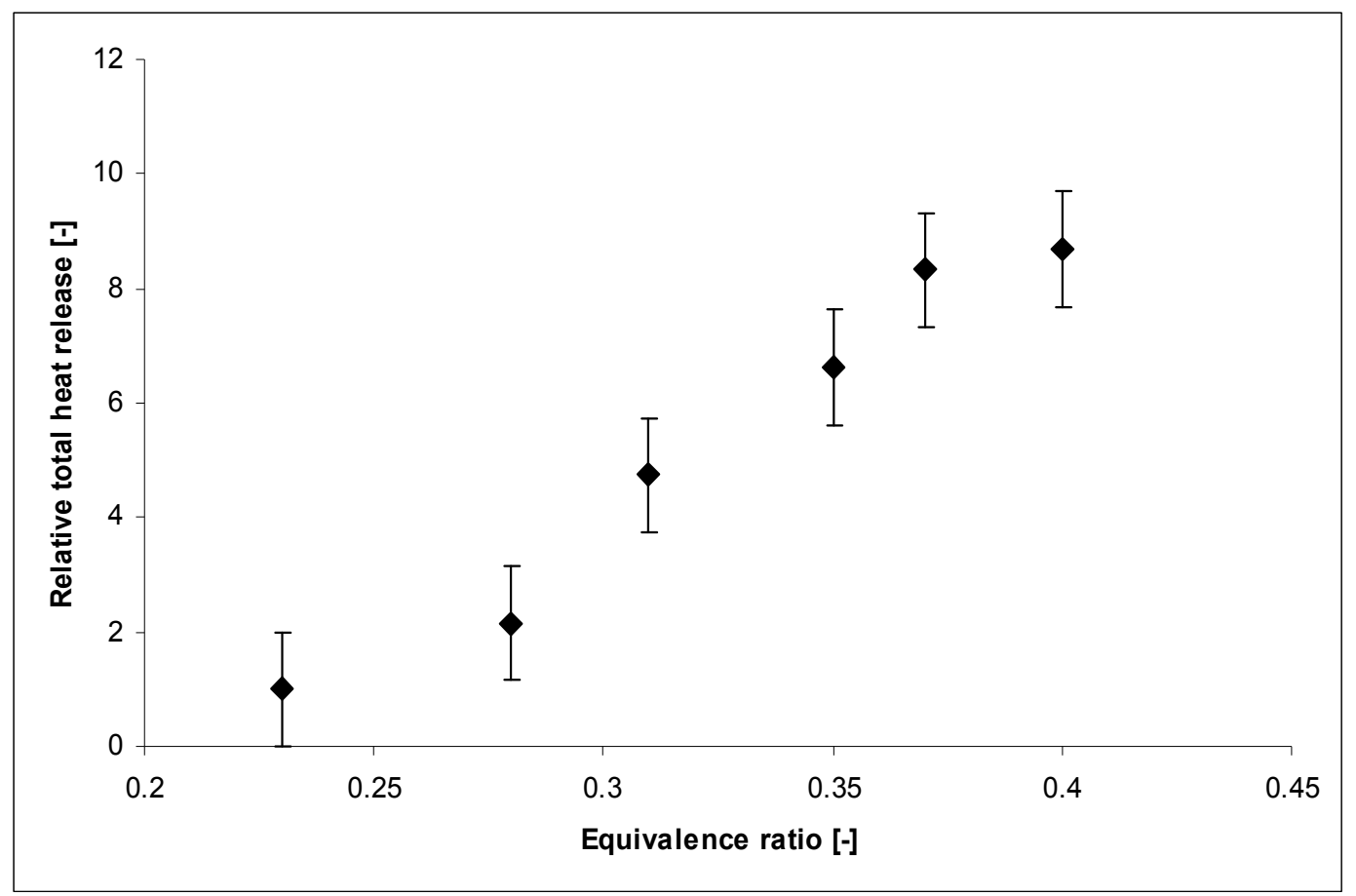

Figure 9: Relative total heat release (with respect to the total heat release at equivalence ratio 0.23 ) at an inlet temperature of $70^{\circ} \mathrm{C}$, a compression ratio of 10,2 , using $n$-heptane as the fuel, varying the equivalence ratio 


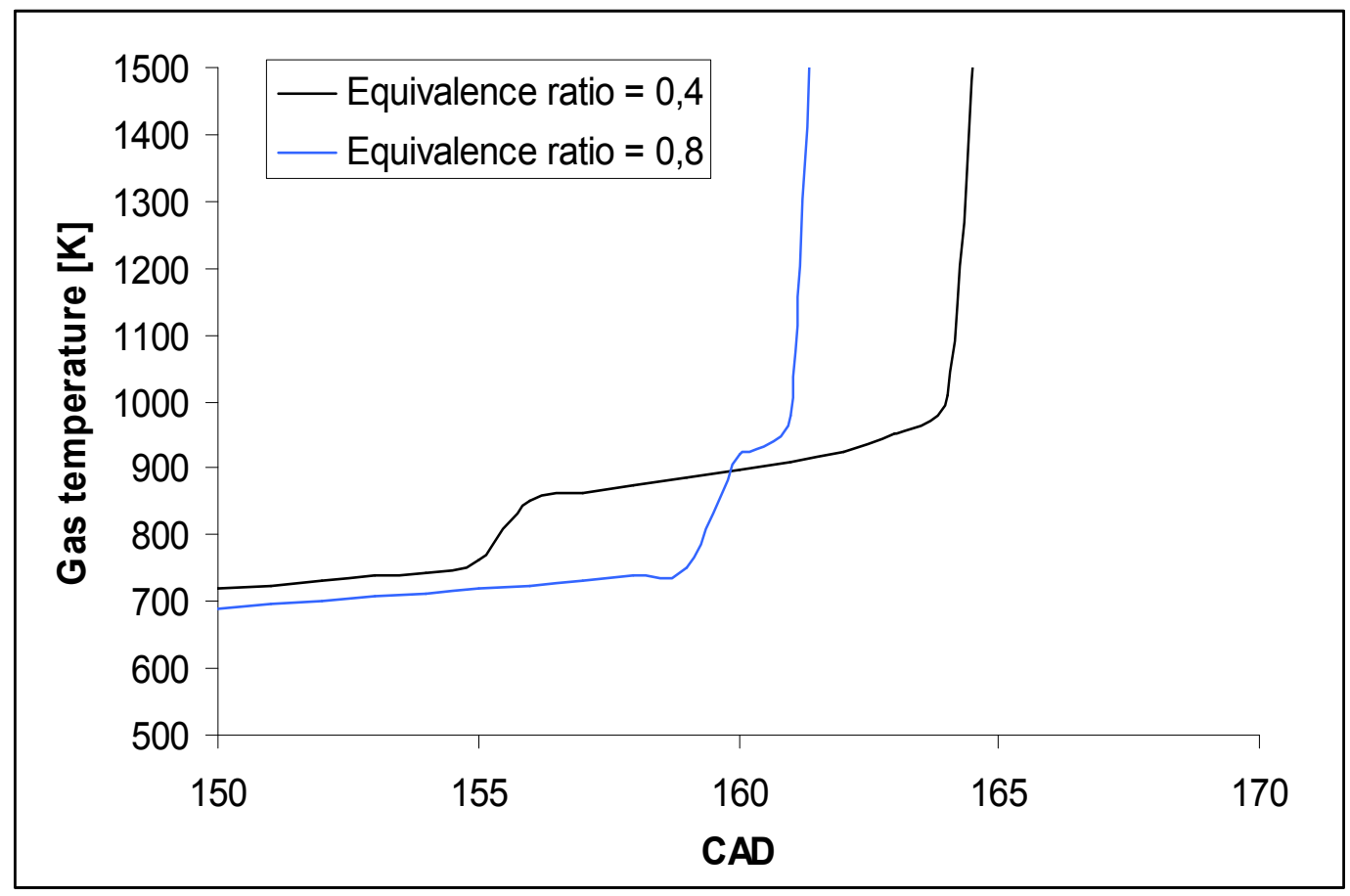

Figure 10: The gas temperatures for equivalence ratios of respectively 0,4 and 0,8 with a compression ratio of 10.2, an inlet temperature of $70^{\circ} \mathrm{C}$ and $n$-heptane as the fuel 


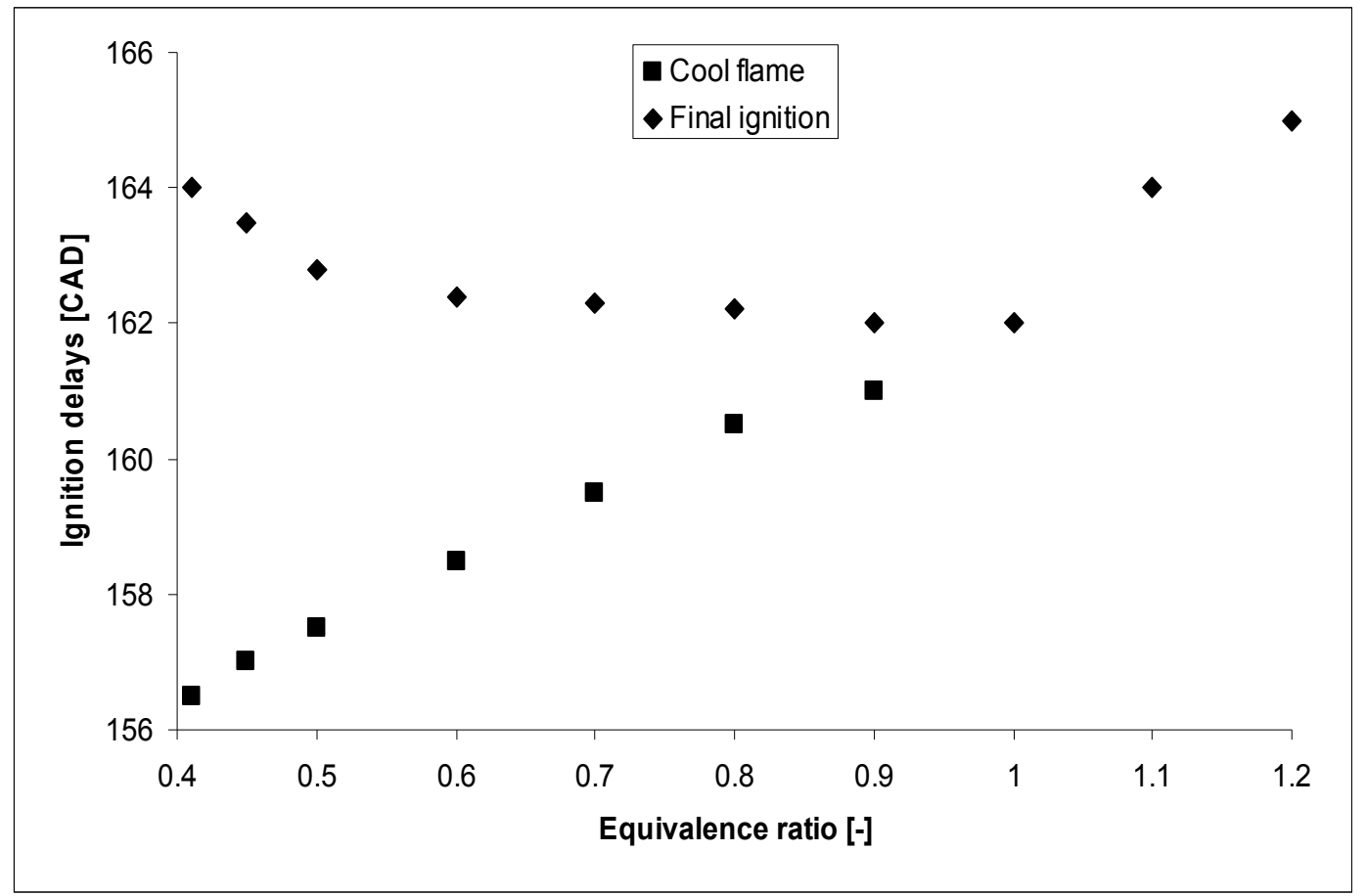

Figure 11: Ignition delays as a function of equivalence ratio at a compression ratio of 10, an inlet temperature of $70{ }^{\circ} \mathrm{C}$ using $n$-heptane as the fuel 


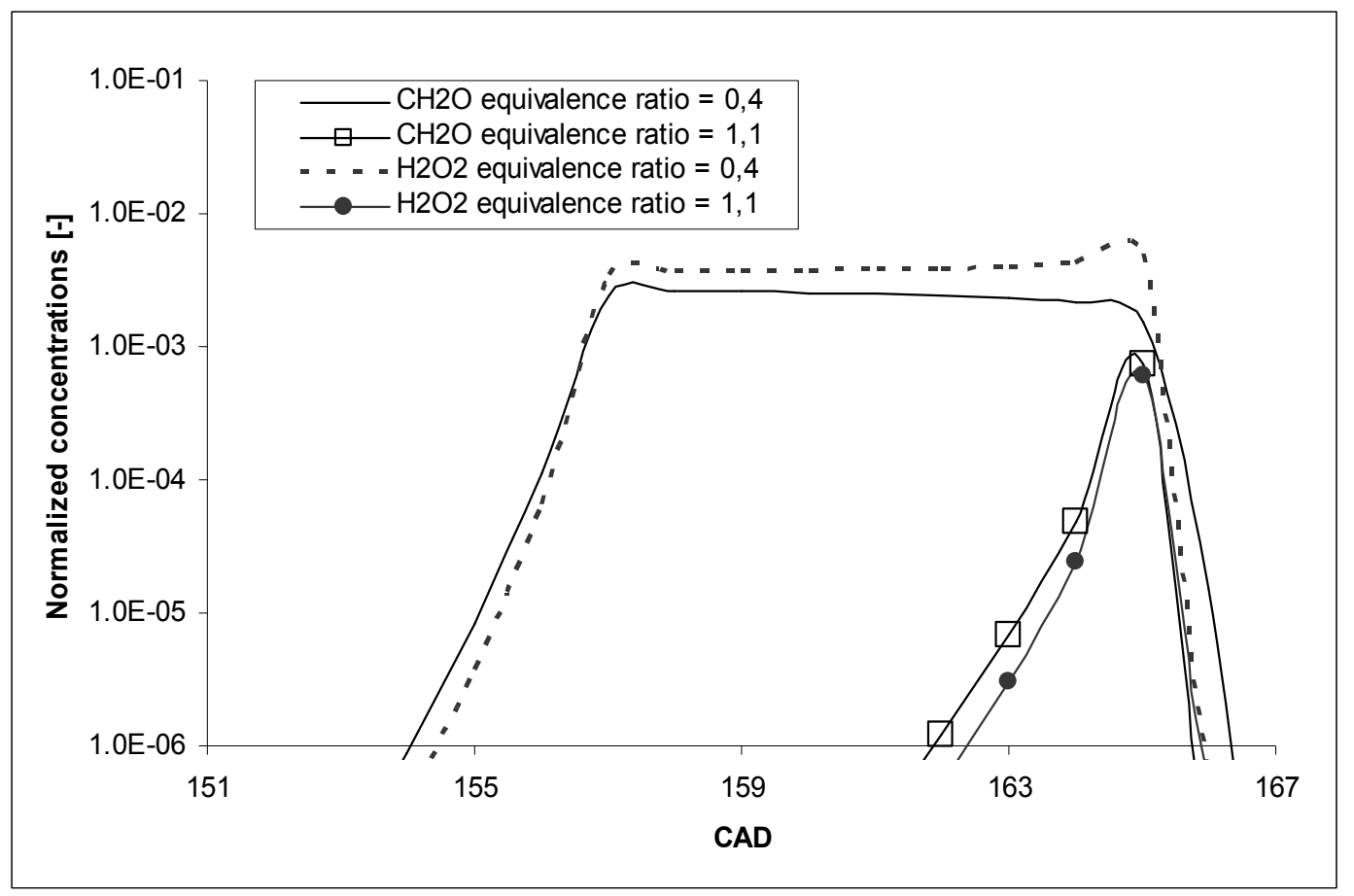

Figure 12: Species profile of $\mathrm{CH}_{2} \mathrm{O}$ and $\mathrm{H}_{2} \mathrm{O}_{2}$ at equivalence ratios 0.4 and 1.1 at a compression ratio of 10.2 , an inlet temperature of $70^{\circ} \mathrm{C}$ using $n$-heptane as the fuel 


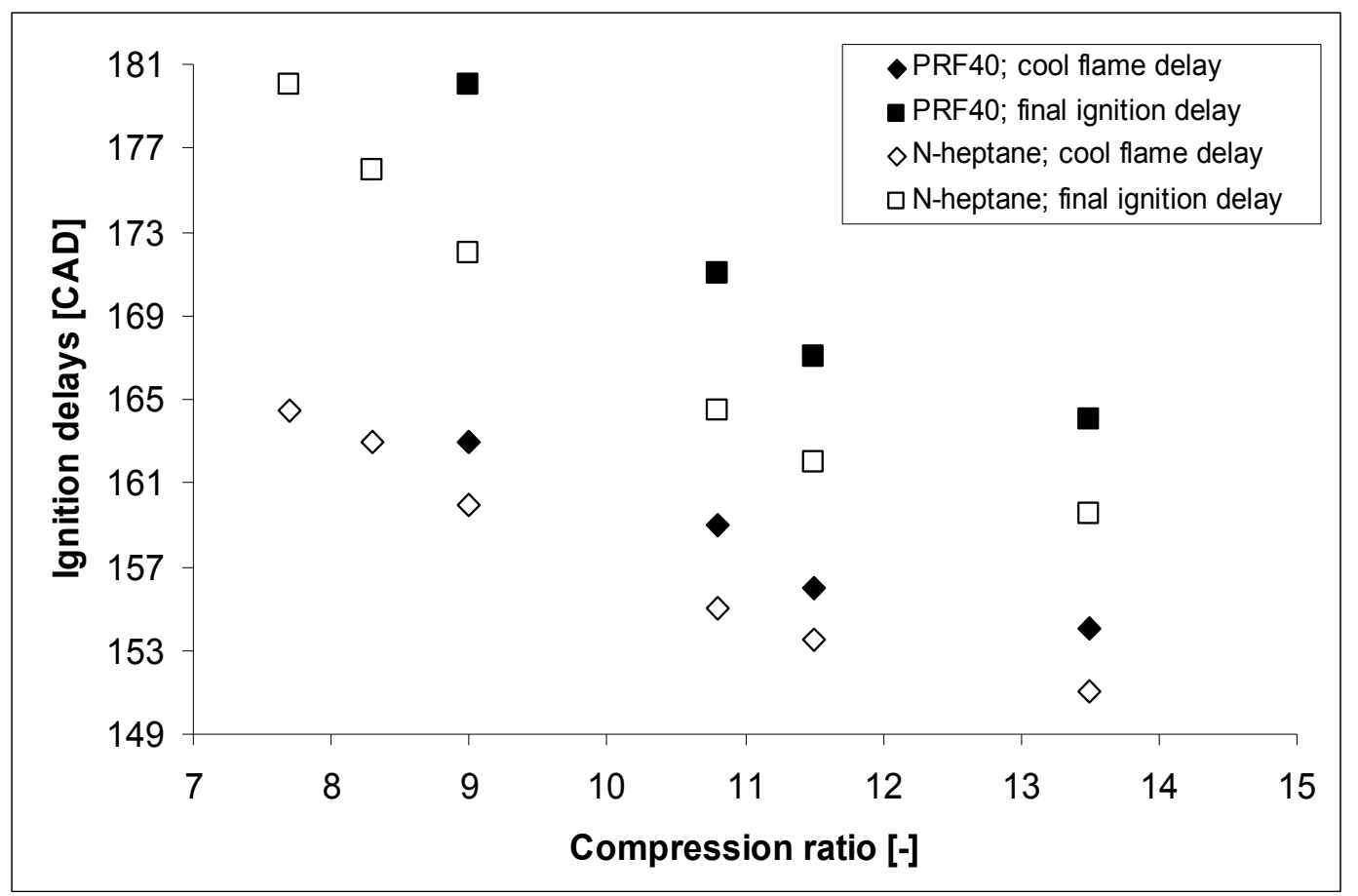

Figure 13: Influence compression ratio on the ignition delays at an inlet temperature of 70 ${ }^{\circ} \mathrm{C}$, an equivalence ratio of 0.33 comparing the fuels $n$-heptane and PRF40 


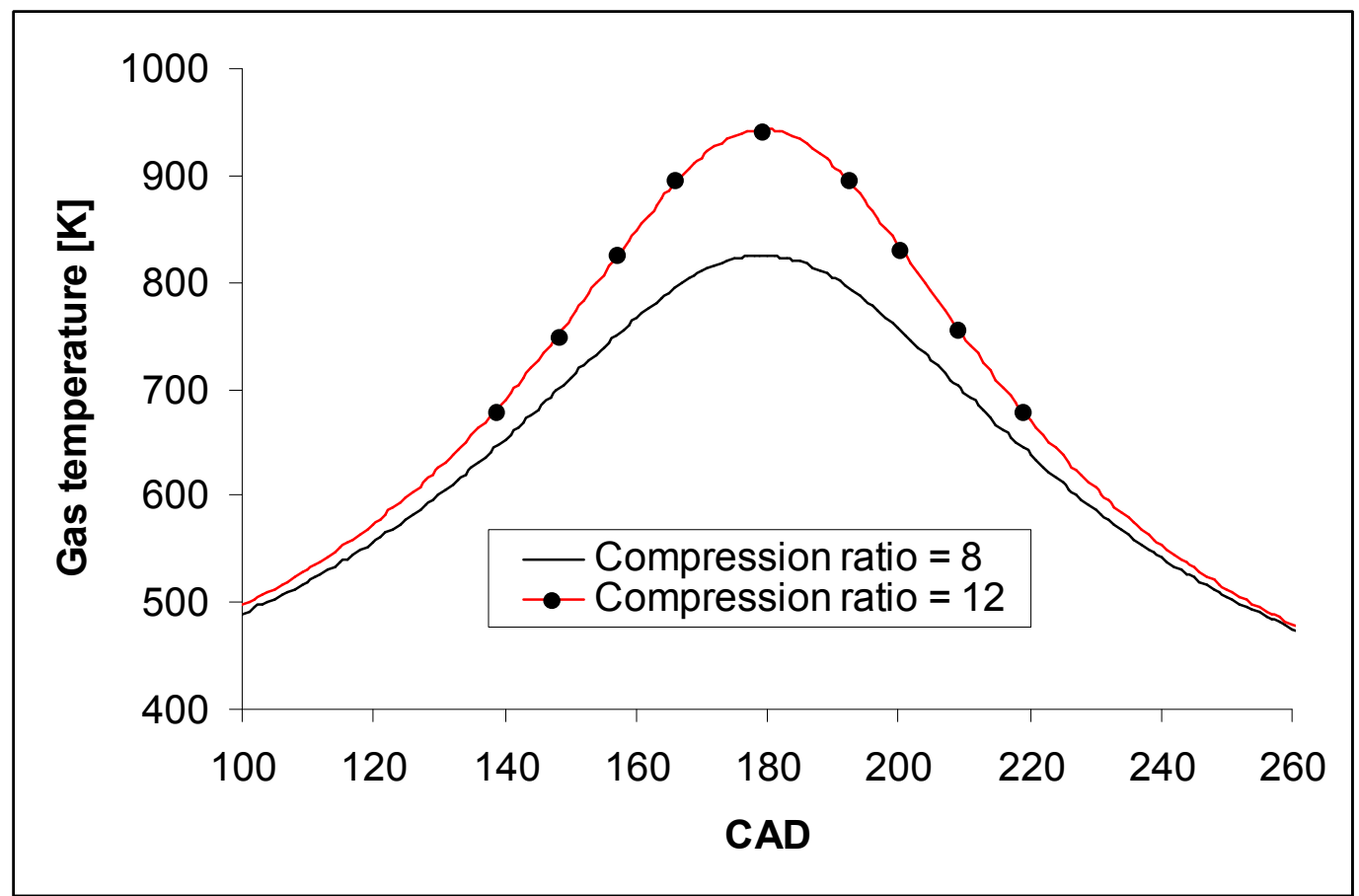

Figure 14: The gas temperature as a function of the compression ratio at an inlet temperature of $70^{\circ} \mathrm{C}$ 


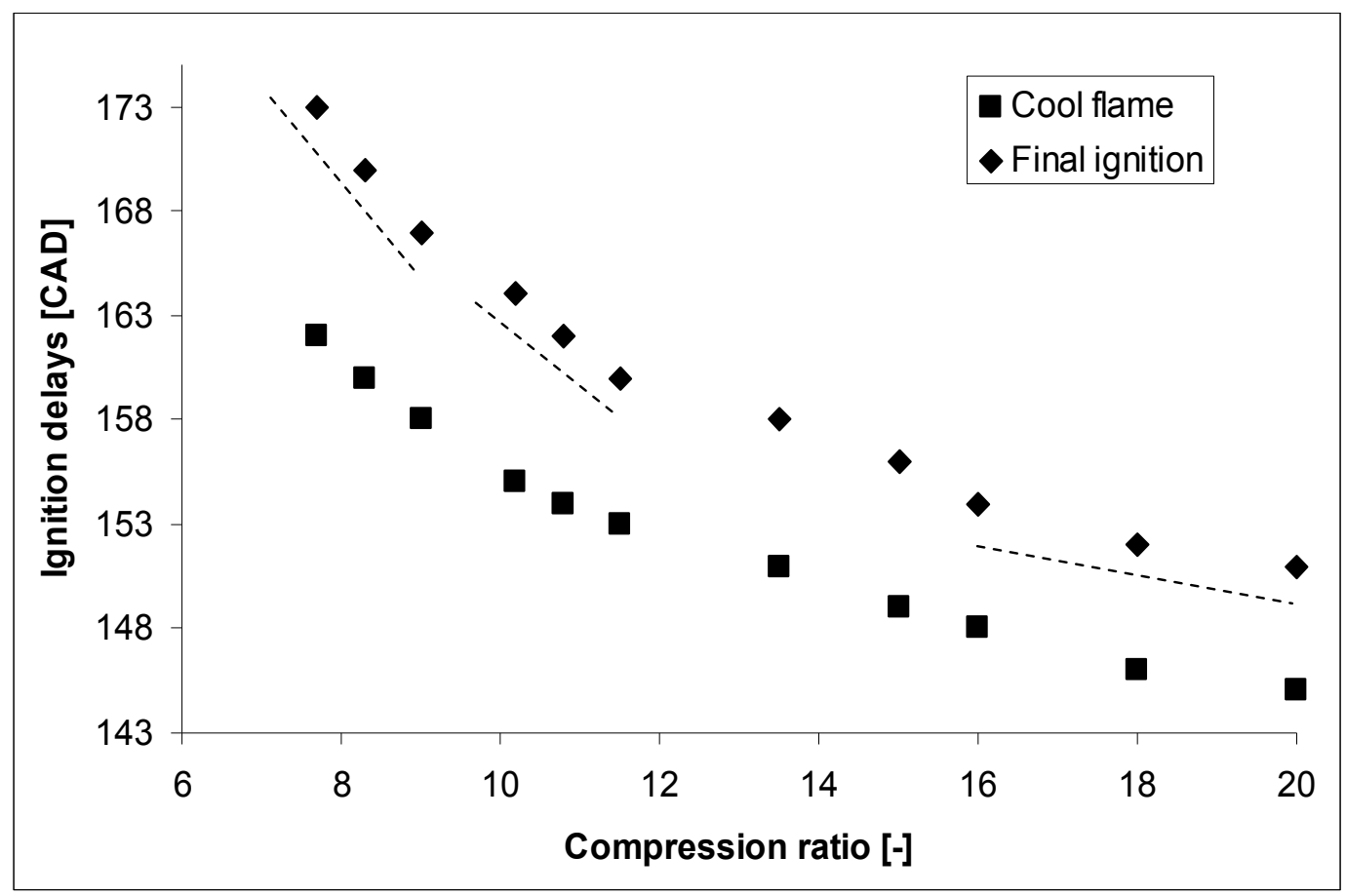

Figure 15: The cool flame and final ignition delays as a function of the compression ratio, at an inlet temperature of $70^{\circ} \mathrm{C}$, an equivalence ratio of 0.41 and $n$-heptane as the fuel 


\section{Table}

\begin{tabular}{|l|l|}
\hline Compression ratio & $4 \sim 14$ \\
\hline Bore & $82.55 \mathrm{~mm}$ \\
\hline Stroke & $114.5 \mathrm{~mm}$ \\
\hline Displacement volume & $611 \mathrm{~cm} 3$ \\
\hline Engine connecting rod to crank radius ratio & 4.44 \\
\hline Exhaust valve open & $140^{\circ} \mathrm{ATDC}$ \\
\hline Exhaust valve close & $15^{\circ} \mathrm{ATDC}$ \\
\hline Intake valve open & $10^{\circ} \mathrm{ATDC}$ \\
\hline Intake valve close & $146^{\circ} \mathrm{BTDC}$ \\
\hline
\end{tabular}

Table 1: CFR engine characteristics 